\title{
Pisiform Bone
}

National Cancer Institute

\section{Source}

National Cancer Institute. Pisiform Bone. NCI Thesaurus. Code C12855.

The medial bone of the proximal row of carpal bones. 